\title{
Aksesibilitas Sumber Pakan Ternak Ruminansia pada Musim Kemarau di Daerah Pertanian Lahan Kering
}

\author{
E. Handayanta, E. T. Rahayu dan M. A. Wibowo \\ Prodi Peternakan, Fakultas Pertanian, Universitas Sebelas Maret \\ Jl. Ir. Sutami 36 A Ketigan Surakarta \\ E-mail:
}

\begin{abstract}
ABSTRAK
Penelitian ini bertujuan untuk mengetahui tingkat kemudahan atau kesulitan peternak sapi potong dalam memperoleh pakan ternak pada musim kemarau di daerah pertanian lahan kering. Penelitian dilaksanakan di Desa Kemejing, Kecamatan Semin, Kabupaten Gunungkidul, Daerah Istimewa Yogyakarta dari bulan Agustus sampai dengan bulan Oktober (musim kemarau). Penelitian menggunakan metode survei dengan teknik Participatory Rural Appraisal (PRA). Tiga puluh (30) peternak digunalan sebagai responden, dengan ketentuan kepemilikan sapi 2-3 ekor, dan memiliki pengalaman beternak minimal 2 tahun. Aksesibilitas terhadap sumber pakan yang diamati terkait dengan asal pakan, jarak lokasi sumber pakan dan atau waktu tempuh, pembelian pakan, ketersediaan tenaga kerja dan waktu yang dibutuhkan dalam mencari pakan. Hasil penelitian dilaporkan secra diskriptif. Hasil penelitian menunjukkan bahwa rerata dari lima peubah yang diamati yaitu asal pakan, jarak dan waktu tempuh, pembelian pakan, ketersediaan tenaga dan waktu pencarian diperoleh skor berturut-turut 0,$77 ; 0,73 ; 0,96 ; 0,71$ dan 0,88 sehingga jumlah skor adalah 4,05 atau berada pada kriteria mudah. Kesimpulan yang dapat diambil dari penelitian ini adalah aksesibilitas terhadap sumber pakan ternak sapi potong pada daerah pertanian lahan kering pada musim kemarau adalah mudah.
\end{abstract}

Kata kunci: Aksesibilitas, lahan kering, musim kemarau, pakan, sapi potong

\section{Accessibility Source of Ruminant's Feed at Dry Season in The Dryland Farming Areas}

\section{ABSTRACT}

This aim of this research to find out the level of easiness or difficulty of beef cattle farmers in obtaining feedstuff in the dry season in dry land farming area. The research was take place in the village of Kemejing, District of Semin, Gunung Kidul Regency, Yogyakarta from August to October (dry season). The research with survey method on the techniques of Participatory Rural Appraisal (PRA). Thirty (30) farmers as respondents, with 2-3 cows ownership provisions, and have a minimum of 2 years on the experience of raising cattle. Accessibility to sources of feedstuff were observed related to the origin of feed, feed resources and location distance or using time, purchase feeds, availability of labor and time needed in looking for feed. Results of the research were reported by descriptive. The results showed that the average of the five observed variables, namely the origin of feed, distance and time, the purchase of feed, labor availability and the search time, obtained score are successively 0.77; 0.73; 0.96; 0.71 and 0.88 , so that the total score was 4.05 and it is called in easy criteria. The conclusion from this study is the accessibility of feed for cattle in dryland farming areas in the dry season is easy.

Keywords: Accessibility, beef cattle, dry land, dry season, feed

\section{PENDAHULUAN}

Pakan ternak ruminansia pada dasarnya adalah hijauan. Kuantitas dan kualitas hijauan pakan sangat menentukan produktifitas ternak ruminansia.
Permasalahan muncul ketika pemanfaatan lahan kering untuk usaha pertanian dan atau peternakan. Oleh karena lahan kering pada umumnya memiliki karakteristik kurang subur (marginal), dan kurang air (ketersediaan air tergantung curah hujan), 
sehingga kurang produktif untuk menghasilkan sumber pakan ternak.

Faktor musim menjadi salah satu faktor penentu ketersediaan pakan, khususnya hijauan. Fluktuasi ketersediaan pakan hijuan secara periodik selalu terjadi setiap tahun, kelebihan pada saat musim penghujan dan kekurangan selama musim kemarau. Kuantitas, kualitas dan kontinuitas hijauan pakan tidak terjamin sepanjang tahun.

Pada musim kemarau peternak berusaha semaksimal mungkin untuk mencukupi persediaan pakan bagi ternaknya. Kemudahan atau kesulitan peternak dalam menyediakan sumber pakan merupakan salah satu faktor yang mempengaruhi kelangsungan usaha pemeliharaan ternaknya. Sering kali dijumpai truck, pick up, sepeda motor, atau sepeda kayuh yang mengangkut rumput dan atau limbah pertanian melintas di jalan raya pada musim kemarau. Hal ini mengindikasikan bahwa peternak dalam memperoleh pakan ternak ruminansia tidak mudah. Peternak mencari hijauan sampai keluar wilayah desa, kecamatan, atau bahkan keluar wilayah kabupaten, dengan jarak tempuh yang dapat mencapai puluhan kilometer. Semua upaya yang dilakukan peternak dalam memperoleh sumber pakan ternaknya memerlukan tenaga dan biaya yang tidak sedikit. Bahkan kadang-kadang untuk mengatasi masalah kesulitan pakan ini peternak menjual ternaknya (biasanya kambing) untuk membeli pakan (sapi) atau kemudian membeli ternak lagi pada musim penghujan pada saat ketersediaan pakan hijauan cukup banyak.

Aksesibilitas adalah ukuran kemudahan yang meliputi waktu, biaya, dan usaha dalam melakukan perpindahan antara tempat-tempat atau kawasan dari sebuah sistem (Magribi, 1999). Adapun ukuran aksesibilitas diantaranya adalah jarak yang ditempuh guna mendapatkan pakan atau mencapai sumber pakan, waktu yang dibutuhkan peternak untuk mencukupi kebutuhan pakan ternak, tenaga kerja pencari pakan, tata guna lahan pertanian baik kondisi lingkungan sekitar usaha peternakan dan pemanfaatan lahan yang dimiliki oleh peternak, dan kondisi ekonomi peternak atau kemampuan peternak dalam membeli pakan serta alat transportasi yang digunakan oleh peternak.

Bertitik tolak dari latar belakang tersebut diatas, maka dilakukan penelitian tentang seberapa mudah atau sulitnya (aksesibilitas) peternak di daerah pertanian lahan kering dalam memperoleh sumber pakan ternak ruminansianya

\section{MATERI DAN METODE}

\section{Lokasi dan Waktu Penelitian}

Penelitian dilaksanakan dari bulan Agustus sampai dengan bulan Oktober (musim kemarau) dengan lokasi penelitian di Desa Kemejing, Kecamatan Semin, Kabupaten Gunungkidul, Daerah Istimewa Yogyakarta. Metode penentuan lokasi penelitian ditentukan secara sengaja (purposive) dengan pertimbangan waktu dan kemampuan serta jangkauan peneliti (Sugiono, 2009).

\section{Teknik Pengumpulan Data}

Data diperoleh dari peternak responden berjumlah 30 orang yang memiliki ternak sapi potong sebanyak 2-3 ekor dan pengalaman beternak lebih dari 2 tahun. Metode pengambilan sampel peternak secara sengaja (purposive sampling) yaitu cara pengambilan sampel dengan maksud atau tujuan tertentu, dengan pertimbangan bahwa sampel (peternak) tersebut memiliki informasi yang diperlukan bagi penelitiannya (Sunyoto, 2009).

Penentuan jumlah responden ini dengan pertimbangan akses lokasi (secara teknis dapat digunakan sebagai lokasi pengambilan sampel), waktu, tenaga dan biaya serta sesuai dengan model penelitian yang bersifatpartisipatif, sehingga dengan syarat-syarat tertentu yang ditetapkan dari jumlah responden tersebut telah dapat 
memberikan gambaran yang mendekati kebenaran.

Penelitian ini adalah penelitian deskriptif dengan menggunakan metode survei (survey method) dengan teknik pengambilan data secara partisipatif (Participatory Rural Appraisal) terhadap para peternak sapi potong dilokasi penelitian. Penelitian deskriptif bertujuan untuk membuat gambaran mengenai situasi atau kejadian atau memberikan gambaran hubungan antar fenomena, menguji hipotesa, membuat prediksi serta implikasi dari suatu masalah yang ingin dipecahkan (Manti et al., 2003). Penelitian survei merupakan penelitian yang mengambil sampel dari satu populasi dan menggunakan kuesioner sebagai alat pengumpulan data yang pokok (Singarimbun dan Efendi, 1995).

\section{Skor Penilaian}

Instrumen penelitian digunakan untuk mengukur nilai variabel yang diteliti guna menghasilkan data kualitatif yang akurat, maka setiap instrumen harus mempunyai skala. Skala pengukuran dalam penelitian ini menggunakan Skala Guttman dengan tujuan mendapatkan jawaban tegas yaitu mudah - sulit yang dibuat dalam bentuk skor. Skor tertinggi adalah 1 (mudah) dan skor terendah adalah 0 (sulit). Total skor dalam penelitian ini adalah 5 yang didapatkan dari penjumlahan lima kriteria (peubah) dimana interval masing-masing dari kriteria itu adalah sama.

Tabel 1. Tingkat Aksesibilitas Sesuai dengan Skor Penilaian

\begin{tabular}{lcl}
\hline Tingkatan & Total Skor & $\begin{array}{c}\text { Tingkat } \\
\text { Aksesibilitas }\end{array}$ \\
\hline Sangat & 5 & Sangat \\
tinggi & 4 & mudah \\
Tinggi. & 3 & Mudah \\
Cukup. & 2 & Cukup \\
Rendah. & 1 & Sulit \\
Sangat & & Sangat sulit \\
rendah & & \\
\hline
\end{tabular}

Konsep aksesibilitas yang mempunyai pengertian bahwa semakin tinggi nilai skor yang diperoleh semakin mudah tingkat aksesibilitasnya atau sebaliknya. Gambaran aksesibilitas sesuai tingkatan menurut kemudahannya dan skor penilaian seperti yang dinyatakan oleh Riwidikdo (2008) seperti berikut ini: Penentuan jenis pakan ternak diperlukan dalam penelitian ini agar proses pengolahan data lebih akurat. Sistem penentuan jenis pakan yang berhubungan dengan proses pemberian skor ditentukan secara sengaja (purposive). Sistem pemberian skor untuk setiap variabel yang diteliti adalah sebagai berikut:

Asal sumber pakan. Cara untuk memberi nilai (skor) pada data asal sumber pakan adalah dengan memberikan nilai 1 jika mudah dan 0 jika sulit. Skor asal sumber pakan berdasarkan kriteria yang ditentukan terlihat seperti Tabel 2.

Tabel 2. Cara dan Kriteria Skor Asal Sumber Pakan.

\begin{tabular}{lll}
\hline \hline \multicolumn{3}{c}{ Asal Sumber Pakan } \\
\hline Skor & $\begin{array}{c}\text { 1 atau } \\
\text { mudah }\end{array}$ & 0 atau sulit \\
\hline Kriteria & $\begin{array}{l}\text { Lahan } \\
\text { sendiri }\end{array}$ & $\begin{array}{l}\text { Lahan orang } \\
\end{array}$ \\
& lain \\
& Sewa & Lahan \\
& & komunal \\
& & Membeli \\
\hline
\end{tabular}

Jarak dan waktu tempuh ke lokasi sumber pakan. Cara untuk memberi nilai (skor) pada data jarak dan waktu tempuh pencarian pakan adalah dengan memberikan nilai 1 jika mudah dan 0 jika sulit. Skor berdasarkan jarak dan waktu tempuh lokasi sumber pakan adalah seperti Tabel 3 .

Ketersediaan tenaga kerja. Cara untuk memberi nilai (skor) pada data ketersediaan tenaga kerja adalah dengan memberikan nilai 1 mudah dan 0 jika sulit. Skor ketersediaan tenaga kerja berdasarkan kriteria yang ditentukan terlihat seperti Tabel 4. 
Tabel 3. Kriteria Skor Jarak dan Waktu Tempuh

\begin{tabular}{|c|c|c|}
\hline \multicolumn{3}{|c|}{ Jarak dan Waktu Tempuh } \\
\hline Skor & 1 atau Mudah & 0 atau Sulit \\
\hline Kriteria & $\begin{array}{l}\text { 1. Jarak }<1 \\
\text { Km non } \\
\text { kendaraan } \\
\text { dengan waktu } \\
\text { tempuh }<10 \\
\text { menit. } \\
2 . \quad \text { Jarak }<3 \\
\text { Km dengan } \\
\text { kendaraan } \\
\text { dengan waktu } \\
\text { tempuh }<5 \\
\text { menit. }\end{array}$ & $\begin{array}{l}\text { 1. Jarak } \\
>1 \mathrm{Km} \text { non } \\
\text { kendaraan } \\
\text { dengan waktu } \\
\text { tempuh }>10 \\
\text { menit. } \\
2 . \quad \text { Jarak } \\
>\quad 3 \quad \mathrm{~km} \\
\text { dengan } \\
\text { kendaraan } \\
\text { dengan waktu } \\
\text { tempuh > } 5 \\
\text { menit. }\end{array}$ \\
\hline
\end{tabular}

Tabel 4. Cara dan Kriteria Skor Ketersediaan Tenaga Kerja

\begin{tabular}{lcc}
\hline \hline \multicolumn{3}{c}{ Ketersediaan Tenaga untuk Mengakses } \\
Pakan
\end{tabular}

Tabel 5. Cara dan Kriteria Skor Waktu Pencarian Pakan

\begin{tabular}{lcc}
\hline \hline & Waktu Pencarian Pakan \\
\hline Skor & 1 atau & 0 atau sulit \\
& mudah & \\
\hline Kriteria & waktu & meningkat \\
& normal & menjadi 2 \\
& & kali lipat dari \\
& & waktu \\
& & normal \\
\hline
\end{tabular}

Waktu pencarian pakan. Cara untuk memberi nilai (skor) pada data waktu pencarian adalah dengan memberikan nilai 1 jika mudah dan nilai 0 jika sulit. Skor waktu pencarian pakan berdasarkan kriteria yang ditentukan terlihat seperti Tabel 5.

Pembelian Pakan. Cara untuk memberi nilai (skor) pada data pembelian pakan adalah memberikan nilai 1 jika mudah dan nilai 0 jika susah. Skor pembelian pakan berdasarkan kriteria yang ditentukan terlihat seperti Tabel 6 .

Setelah data dikumpulkan maka selanjutnya akan ditabulasikan untuk mempermudah proses pembacaan data sesuai peubah penelitian dengan cara mencari rata-rata nilai (skor) yang diperoleh dengan rumus matematika (Sudjana, 2002):

$$
\mathbf{X}=\frac{\sum \mathbf{x}}{\mathbf{n}}
$$

Keterangan : $\mathrm{X}=$ rata-rata $($ mean $) ; \sum \mathrm{x}=$ jumlah skor semua responden; $\mathrm{n}=$ Jumlah responden

Untuk mengetahui skor maksimal dan skor kemudahan/kesulitan maka digunakan rumus:

\section{Skor Maksimal $=$ Parameter $\mathbf{x}$ Skor Tertinggi x Jumlah Responden}

\section{Skor Kemudahan atau Kesulitan $=($ Jumlah Rata-Rata Skor) / (Jumlah Jenis Pakan yang Diskor)}

Keterangan: skor maksimal: Penjumlahan skor dari semua parameter berdasarkan jumlah responden; Skor kemudahan/ kesulitan: Hasil akhir perhitungan skor yang menunjukkan tingkat kemudahan (Arikunto, 2001).

Tabel 6. Cara dan Kriteria Skor Pembelian Pakan.

\begin{tabular}{lcc}
\hline \hline \multicolumn{3}{c}{ Pembelian Pakan } \\
\hline Skor & 1 atau mudah & 0 atau sulit \\
\hline Kriteria & $\begin{array}{c}\text { tidak membeli } \\
\text { pakan }\end{array}$ & $\begin{array}{c}\text { membeli } \\
\text { pakan }\end{array}$ \\
\hline
\end{tabular}

\section{HASIL DAN PEMBAHASAN}

\section{Jenis Pakan yang Diberikan sebagai Pakan Ternak}

Dari hasil penelitian didapatkan bahwa terdapat beraneka ragam jenis sumber pakan yang diberikan oleh peternak untuk mencukupi kebutuhan pakan ternak yang dipelihara seperti terlihat pada Tabel 7. 
Tabel 7. Jenis pakan ternak yang diberikan pada sapi potong pada musim kemarau

\begin{tabular}{|c|c|c|}
\hline No & Penggolongan & Tananam Pakan Ternak \\
\hline 1 & Rumput-rumputan & Rumput gajah, rumput alam. \\
\hline 2 & Kacang-kacangan & Daun turi, daun lamtoro. \\
\hline 3 & Limbah pertanian & $\begin{array}{l}\text { Jerami padi, jerami jagung, jerami kacang tanah, } \\
\text { jerami kacang. kedelai, daun ketela pohon, jerami } \\
\text { kacang hijau, jerami kacang panjang, dan kulit } \\
\text { singkong, }\end{array}$ \\
\hline 4 & $\begin{array}{l}\text { Daun-daunan dari tanaman } \\
\text { pohon }\end{array}$ & $\begin{array}{l}\text { Daun akasia, daun mahoni, daun dan batang } \\
\text { pisang, daun bayam, daun munggur, daun wora- } \\
\text { wari, daun dadap, daun mangga, daun johar, daun } \\
\text { randu, daun jambu, daun kluwih, daun nangka, } \\
\text { daun bambu, daun ganyong, daun blimbing, daun } \\
\text { sono, daun duwet, daun bunga sepatu, dan daun } \\
\text { pepaya }\end{array}$ \\
\hline
\end{tabular}

\section{Hasil dan Analisis Skoring}

Hasil skoring berdasarkan jenis pakan yang diberikan oleh peternak sapi potong pada saat musim kemarau seperti terlihat pada Tabel 8 .

\section{Aksesibilitas Berdasarkan Asal Pakan}

Rata-rata skor tingkat kemudahan atau kesulitan berdasarkan asal pakan adalah 0,77 . Hal ini menunjukkan bahwa aksesibilitas berdasarkan asal pakan adalah mudah. Hal itu disebabkan karena pakan yang digunakan untuk mencukupi kebutuhan ternak adalah berasal dari lahan sendiri baik berupa pekarangan, sawah dan tegalan yang dikelola peternak untuk bercocok tanam berbagai komoditas tanaman pangan dan pakan ternak.

Pakan selama musim kemarau diperoleh dari lahan orang lain, lahan komunal dan membeli terjadi pada jenis pakan tertentu (pembelian pakan berupa jerami padi) sehingga sesuai dengan pendapat Ruswendi (2004) yang menyatakan bahwa pada umumnya peternak telah mengupayakan agar lahannya tetap diolah sepanjang tahun dengan menerapkan pola tanam maksimal guna mencukupi kebutuhan petani pemilik lahan.

\section{Aksesibilitas Berdasarkan Jarak dan Waktu Tempuh}

Rata-rata skor tingkat kemudahan atau kesulitan berdasarkan jarak dan waktu tempuh adalah 0,73. Hal ini menujukkan bahwa aksesibilitas berdasarkan jarak dan waktu tempuh adalah mudah. Jarak dan waktu tempuh dalam proses pencarian pakan ternak yang dilakukan oleh peternak tidak jauh dan tidak membutuhkan waktu yang lama untuk mencapai lokasi sumber pakan ternak, serta didukung sarana atau alat transportasi yang dimiliki dan digunakan oleh peternak.

Kemudahan dalam mencapai lokasi sumber pakan ternak disebabkan karena ketersediaan sarana transportasi yang dimiliki dan digunakan oleh peternak serta medan yang dilalui oleh para peternak. Hal ini sesuai pendapat Miro (2005) yang menyatakan bahwa tingkat aksesibilitas wilayah bisa diukur berdasarkan pada beberapa variabel yaitu ketersediaan jaringan jalan, jumlah alat transportasi, panjang jalan, lebar jalan, dan kualitas jalan. 


\section{Skor Aksesibilitas Berdasarkan Ketersediaan Tenaga Kerja}

\begin{abstract}
Rata-rata skor tingkat kemudahan atau kesulitan berdasarkan ketersediaan tenaga kerja adalah 0,96. Hal ini menunjukkan bahwa aksesibilitas berdasarkan ketersediaan tenaga kerja adalah mudah. Ketersediaan tenaga yang dimiliki oleh rumah tangga peternak dalam mengakses sumber pakan disebabkan karena peternak di musim kemarau tidak banyak beraktifitas dalam bercocok tanam di lahan yang mereka miliki sehingga tidak terlalu banyak mengeluarkan tenaga untuk menggarap lahan dan peternak lebih berkosentrasi pada usaha ternak mereka (tersedia cukup waktu untuk mencari pakan ternak).
\end{abstract}

\section{Aksesibilitas Berdasarkan Waktu Pencarian Pakan}

Rata-rata skor tingkat kemudahan atau kesulitan berdasarkan waktu pencarian pakan adalah 0,71 . Hal ini mengindikasikan bahwa skor aksesibilitas berdasarkan waktu pencarian pakan adalah mudah. Waktu pencarian pakan yang masih tergolong normal artinya, peternak tidak membutuhkan waktu yang lama hingga mencapai 2 kali lipat waktu normal disebabkan karena dalam mengakses pakan, peternak mempertimbangkan waktu yang dimiliki untuk memperoleh hasil yang semaksimal mungkin. Para peternak juga mencari pakan di lokasi yang telah direncanakan sesuai dengan waktu panen (siklus panen) untuk jenis tanaman pakan ternak yang ingin diberikan. Kesulitan yang ada dalam proses pencarian pakan yang membutuhkan waktu yang lebih lama sampai 2 kali lipat disebabkan karena peternak sudah tidak memiliki persediaan tanaman pakan ternak yang siap untuk dipanen sehingga peternak harus mencari sumber pakan baru atau mengumpulkan pakan yang belum siap panen sedikit demi sedikit yang tentunya akan membutuhkan waktu pencarian yang lebih lama.

\section{Aksesibilitas Berdasarkan Pembelian Pakan}

Rata-rata skor tingkat kemudahan atau kesulitan berdasarkan aktifitas pembelian pakan adalah 0,88. Hal ini menunjukkan bahwa skor aksesibilitas berdasarkan pembelian pakan adalah mudah. Secara umum para peternak tidak membeli pakan dalam menyediakan pakan untuk ternaknya Pembelian pakan hanya terjadi pada jenis pakan jerami padi yang dapat dibeli dalam jumlah banyak dan dapat disimpan dalam waktu yang relatif lama. Para peternak di daerah penelitian memilih untuk bertahan dengan memberikan pakan seadanya yang tersedia di lingkungan sekitar. Sumber-sumber pakan ternak inkonvensionil, seperti daun-daunan tanaman pohon (Tabel 7), dapat dimanfaatkan pada saat musim kemarau, sehingga ternak ternak dapat bertahan (survive) dan pakan tidak perlu dibeli.

\section{Aksesibilitas Secara Keseluruhan}

Gambaran kemudahan dalam mengakses sumber pakan ternak berdasarkan perhitungan seluruh parameter dalam penelitian yang meliputi asal pakan, jarak dan waktu tempuh lokasi sumber pakan, pembelian pakan, ketersediaan tenaga yang dimiliki peternak dan waktu pencarian adalah sebagai berikut:

Skor kemudahan/kesulitan $=$ (jumlah rata-rata skor) / (jumlah jenis pakan yang di skor) $=32,45 / 8=4,05$

Hasil skor total yaitu 4,05, sehingga disimpulkan bahwa aksesibilitas terhadap sumber pakan ternak ruminansia adalah mudah. Kriteria mudah disimpulkan atas dasar skor total parameter yang diteliti dan didukung oleh beberapa faktor lain diantaranya adalah karena para peternak mempertimbangkan kemampuannya dalam beternak sapi potong dan para peternak di daerah penelitian berpendapat bahwa mereka masih mampu untuk memelihara ternak sapi 
Tabel 8. Skor Aksesibilitas Pakan Ternak

\begin{tabular}{llccccccc}
\hline \hline No & $\begin{array}{c}\text { Jenis } \\
\text { pakan }\end{array}$ & $\begin{array}{c}\text { Asal } \\
\text { pakan }\end{array}$ & $\begin{array}{c}\text { Jarak } \\
\text { dan } \\
\text { waktu } \\
\text { tempuh }\end{array}$ & $\begin{array}{c}\text { Keterse- } \\
\text { diaan } \\
\text { tenaga } \\
\text { kerja }\end{array}$ & $\begin{array}{c}\text { Waktu } \\
\text { pencarian }\end{array}$ & $\begin{array}{c}\text { Pembe- } \\
\text { lian } \\
\text { pakan }\end{array}$ & Jumlah & $\begin{array}{c}\text { rata- } \\
\text { rata }\end{array}$ \\
\hline 1 & $\begin{array}{l}\text { J. padi } \\
2\end{array}$ & 3 & 13 & 21 & 20 & 9 & 66 & 2,20 \\
Rumput & 30 & 26 & 30 & 30 & 28 & 144 & 4,80 \\
3 & $\begin{array}{l}\text { Jajah } \\
\text { J. jagung }\end{array}$ & 30 & 26 & 30 & 30 & 27 & 143 & 4,77 \\
4 & $\begin{array}{l}\text { Rumput } \\
\text { alam }\end{array}$ & 27 & 25 & 27 & 25 & 27 & 131 & 4,85 \\
5 & $\begin{array}{l}\text { J. kc } \\
\text { tanah }\end{array}$ & 27 & 23 & 27 & 3 & 27 & 107 & 3,96 \\
6 & $\begin{array}{l}\text { Daun } \\
\text { pisang }\end{array}$ & 25 & 21 & 27 & 24 & 27 & 124 & 4,59 \\
7 & $\begin{array}{l}\text { Daun } \\
\text { mahoni }\end{array}$ & 14 & 14 & 26 & 14 & 26 & 94 & 3,61 \\
8 & $\begin{array}{l}\text { Daun } \\
\text { akasia }\end{array}$ & 14 & 14 & 24 & 12 & 24 & 88 & 3,67 \\
\hline Jumlah skor & 170 & 162 & 212 & 158 & 195 & 897 & 32,45 \\
Skor maksimal \\
Rata- rata skor
\end{tabular}

potong dalam jumlah 2-3 ekor karena peternak berasumsi bahwa lahan yang mereka miliki masih mampu untuk mencukupi penyediaan pakan ternak mereka sehingga peternak tidak mengeluarkan biaya yang terlalu banyak untuk pembelian pakan. Disamping itu, pemeliharaan ternak sapi pada masyarakat desa secara tradisional bertujuan untuk tabungan hidup, pekerjaan sampingan, secara tidak langsung sebagai bentuk usaha peternak dalam pemanfaatan limbah pertanian.

Kondisi jalan di daerah penelitian sebagian besar sudah baik yaitu berupa jalan aspal dan jalan konblok (semen) sehingga mempermudah peternak dalam mengakses sumber pakan. Tingkat aksesibilitas itu tinggi atau rendah (mudah atau sulit) adalah ditentukan oleh banyaknya sistem jaringan yang tersedia pada daerah tersebut. Semakin banyak sistem jaringan yang tersedia pada daerah tersebut maka semakin mudah aksesibilitas yang didapat begitu pula sebaliknya semakin rendah tingkat aksesibilitas yang didapat maka semakin sulit daerah itu dijangkau dari daerah lainnya.

Kondisi topografi daerah penelitian yang datar, memperkuat tingginya aksesibilitas dalam menjangkau sumber pakan, diamana faktor yang mempengaruhi fungsi tinggi-rendahnya aksesibilitas salah satunya adalah topografi, sebab kondisi topografi yang sulit dapat menjadi penghalang bagi kelancaran untuk mengadakan interaksi di suatu daerah.

\section{KESIMPULAN DAN SARAN}

\section{Kesimpulan}

Hasil penelitian yang telah dilakukan dapat disimpulkan bahwa aksesibilitas sumber pakan ternak sapi potong di daerah pertanian kering pada musim kemarau berdasarkan asal sumber pakan, jarak dan waktu tempuh, pembelian pakan, ketersediaan tenaga dan waktu pencarian pakan di Desa Kemejing Kecamatan Semin Kabupaten Gunungkidul adalah mudah. 


\section{Saran}

Diperlukan penelitian lebih lanjut untuk mengetahui aksesibilitas sumber pakan dilihat dari parameter yang lain agar lebih rinci dan akurat, penelitian aksesibilitas dengan teknik skoring yang berbeda, dan mengenai jumlah (kuantitas) dan kualitas pakan yang diberikan oleh peternak sapi potong agar terdapat standart yang lebih baik dalam penentuan skor.

\section{DAFTAR PUSTAKA}

Arikunto, S. 2001. Dasar-Dasar Evaluasi Pendidikan. Bumi Aksara, Jakarta.

Magribi, M. 1999. Geografi Transportasi. PPS UGM, Yogyakarta.

Manti, I. Azmi, E. Priyotomo dan D. Sitompul. 2003. Kajian Sosial Ekonomi Sistem Integrasi Sapi dengan Kelapa Sawit (SISKA). Prosiding Lokakarya Nasional Sistem Integrasi Kelapa-Sapi. Bengkulu, September 2003. Pusat Penelitian dan Pengembangan Peternakan, Bogor.

Miro, F. 2005. Perencanaan Transportasi. Erlangga, Jakarta.

Riwidikdo, H. 2008. Statistik Kesehatan. Mitra Cendekia Press, Yogyakarta.

Ruswendi. 2004. Analisis Potensi Sumberdaya Pakan Untuk Pabrik Pakan Ternak Sapi Potong di Kabupaten Gunungkidul. Tesis S2. PPS UGM, Yogyakarta.

Sudjana. 2002. Metode Statistik. Tarsito, Bandung.

Sugiono, 2009. Metode Penelitian Pendidikan Pendekatan Kuantitatif, Kualitatif dan $R \& D$. Alfabeta, Bandung

Sunyoto, D. 2009. Analisis Regresi dan Uji Hipotesis. Media Pressindo, Yogyakarta. 